\title{
Prophylaxis of chemotherapy-induced febrile neutropenia with granulocyte colony-stimulating factors: where are we now?
}

\author{
Matti Aapro • Jeffrey Crawford • Didier Kamioner
}

Received: 4 September 2009 /Accepted: 7 January 2010/Published online: 27 February 2010

(C) The Author(s) 2010. This article is published with open access at Springerlink.com

\begin{abstract}
Updated international guidelines published in 2006 have broadened the scope for the use of granulocyte colony-stimulating factor (G-CSF) in supporting delivery of myelosuppressive chemotherapy. G-CSF prophylaxis is now recommended when the overall risk of febrile neutropenia $(\mathrm{FN})$ due to regimen and individual patient factors is $\geq 20 \%$, for supporting dose-dense and doseintense chemotherapy and to help maintain dose density where dose reductions have been shown to compromise outcomes. Indeed, there is now a large body of evidence for the efficacy of G-CSFs in supporting dose-dense chemotherapy. Predictive tools that can help target those patients who are most at risk of FN are now becoming available. Recent analyses have shown that, by reducing the risk of FN and chemotherapy dose delays and reductions, G-CSF prophylaxis can potentially enhance survival benefits in patients receiving chemotherapy in curative settings. Accumulating data from 'real-world' clinical practice settings indicate that patients often receive abbreviated courses of daily G-CSF and consequently obtain a reduced level of FN protection. A single dose of PEGylated G-CSF (pegfilgrastim) may provide a more effective, as well as a
\end{abstract}

M. Aapro ( $\bowtie)$

IMO Clinique de Genolier,

1 route du Muids,

1272 Genolier, Switzerland

e-mail: maapro@genolier.net

J. Crawford

Department of Medicine, Duke University Medical Centre,

Durham, USA

D. Kamioner

Hôpital Privé de l'Ouest Parisien,

Trappes, France more convenient, alternative to daily G-CSF. Prospective studies are needed to validate the importance of delivering the full dose intensity of standard chemotherapy regimens, with G-CSF support where appropriate, across a range of settings. These studies should also incorporate prospective evaluation of risk stratification for neutropenia and its complications.

Keywords Cancer treatment . Colony-stimulating factors . Neutropenia $\cdot$ Guidelines

\section{Introduction}

Neutropenia is a major dose-limiting toxicity of myelosuppressive chemotherapy that predisposes patients to serious infections. Febrile neutropenia (FN), generally defined as fever (single oral temperature $\geq 38.3^{\circ} \mathrm{C}$ or $\geq 38.0^{\circ} \mathrm{C}$ for $>1 \mathrm{~h}$ ) with grade $3 / 4$ neutropenia (absolute neutrophil count [ANC] $<1.0$ or $\left.<0.5 \times 10^{9} / 1\right)$, is associated with substantial morbidity, escalation of costs and mortality risk [1-5]. Severe neutropenia and FN episodes are also major drivers of chemotherapy dose delays and reductions [6-8], which have been shown to compromise survival outcomes in various curative settings [7, 9-13].

Prophylaxis with recombinant granulocyte colonystimulating factors (G-CSFs) reduces the severity and duration of chemotherapy-induced neutropenia and the consequent risk of FN [14, 15] and is playing an increasingly broad role in supporting the delivery of myelosuppressive chemotherapy [16-18].

The aim of this article is to review recent developments in the use of G-CSFs in this setting. A literature search was conducted using the search terms "granulocyte colonystimulating factor", "leukaemia", "lymphoma" and "solid 
tumours". Additional studies were identified by handsearching reference lists of retrieved papers. Conference websites were searched for recent reports (2006 onwards) not covered by published literature, using the search terms "G-CSF", "granulocyte colony-stimulating factor", "neutropenia", "filgrastim", "lenograstim" and "pegfilgrastim".

\section{Who should receive G-CSFs?}

Official guidelines from Europe and the USA now agree that primary G-CSF prophylaxis should be given when the overall risk of FN due to regimen and patient factors is $\geq 20 \%$ [16-20]. Prior to 2006, primary G-CSF prophylaxis was recommended for chemotherapy regimens associated with a relatively high FN risk of $40 \%$ [21]. However, data showed that clinical benefit was obtained at a much lower threshold of risk [22, 23], and the importance of individual patient risk factors was also recognised [16, 17].

Regimens with an overall risk of FN of $\geq 20 \%$ include anthracycline/taxane regimens that are used for treatment of breast cancer, cyclophosphamide, doxorubicin, vincristine, prednisone (CHOP)-like regimens used for non-Hodgkin's lymphoma (NHL) $[16,18]$ and the docetaxel, cisplatin and 5 -fluorouracil (DCF/TPF) regimen used for gastric [24] and head and neck $[25,26]$ cancer.

Immunomodulatory derivatives of thalidomide such as lenalidomide have shown promise for the treatment of myeloma [27, 28]. These agents appear to induce neutropenia by transiently blocking the maturation of granulocytes, rather than via stem cell toxicity, suggesting that this might be prevented by G-CSF administration [29]. Further work is required to define the risk of FN with these agents.

For regimens that are associated with a $10-20 \%$ risk of $\mathrm{FN}$, individual patient factors must also be considered when determining the need for G-CSF support (Fig. 1). There is high-level evidence for older age, advanced-disease stage and $\mathrm{FN}$ occurrence in a first or previous chemotherapy cycle as risk factors for FN [16]. Other factors that have been reported to increase risk include the presence of comorbidities and poor performance/nutritional status [1618]. As age $>65$ years is consistently shown to be associated with increased FN risk, G-CSF prophylaxis should be considered for supporting chemotherapy delivery in all elderly patients receiving myelotoxic chemotherapy [30].

Historically, it was common practice to reduce the chemotherapy dose instead of administering G-CSF in atrisk patients, but this strategy risks obtaining suboptimal results. Rather, G-CSF use should be guided by the intent of treatment (i.e., whether curative or for prolonging survival as opposed to palliative). If reduction in chemotherapy dose intensity or density is associated with poor prognosis or where dose-dense or dose-intense chemotherapy regimens have survival benefits, G-CSF prophylaxis should be used. Where this is not crucial, use of a less myelosuppressive chemotherapy regimen or dose/schedule modification can be considered [16].

\section{G-CSF to support chemotherapy: new data}

Anthracycline/taxane regimens, particularly doxorubicincontaining regimens, have become a standard of care in breast cancer. Docetaxel, doxorubicin and cyclophosphamide (TAC) is a combination regimen that has high efficacy in the adjuvant setting, reducing the risk of death by $30 \%$ compared to fluorouracil, doxorubicin and cyclophosphamide (FAC) [31]. While TAC is associated with a relatively high risk of $\mathrm{FN}(>20 \%)$ and other toxicities, delivery is feasible with effective growth factor support $[32,33]$. As well as reducing the risk of $\mathrm{FN}$, G-CSF prophylaxis has also been reported to attenuate non-haematological toxicities such as aesthenia/anorexia, stomatitis/mucositis and diarrhoea in TAC recipients [32, 33]. It is unknown whether this is a direct protective effect or related to decreased cytokine release via the reduced risk of infection.

Elderly patients have often not been considered as candidates for full-dose aggressive chemotherapy, but there is a growing body of evidence to show that, with adequate G-CSF support, delivery of myelosuppressive chemotherapy [34-37], including taxane-containing (neo)adjuvant regimens [36, 37] and dose-dense CHOP (discussed in a later section), is feasible in this population.

Recent prospective data from a large communitybased study have confirmed previous observations that FN is most common in the first cycle of chemotherapy [38], and this underlines the need to start G-CSF from the first cycle in appropriate patients. Prophylactic use of GCSF (pegfilgrastim) from cycle 1 was shown to reduce the incidence of $\mathrm{FN}$ by approximately $60 \%$ compared with reactive use (initiated after cycle 1 at the physician's discretion) in elderly patients (aged $\geq 65$ years; $n=852$ ) receiving a range of mild to moderately myelosuppressive chemotherapy regimens for solid tumours (lung, breast or ovarian cancer) or NHL [35]. Among those with solid tumours, $\mathrm{FN}$ occurred in $10 \%$ (95\% confidence interval [CI] $7-14 \%$ ) of the reactive-use group versus $4 \%(95 \% \mathrm{CI}$ $2-6 \%$ ) of the pegfilgrastim primary prophylaxis group ( $p=$ $0.001)$. Among NHL patients, FN occurred in $37 \%(95 \%$ CI $26-49 \%)$ of the reactive-use versus $15 \%(95 \%$ CI 8 $25 \%$ ) of the pegfilgrastim primary prophylaxis group $(p=0.004)$. 


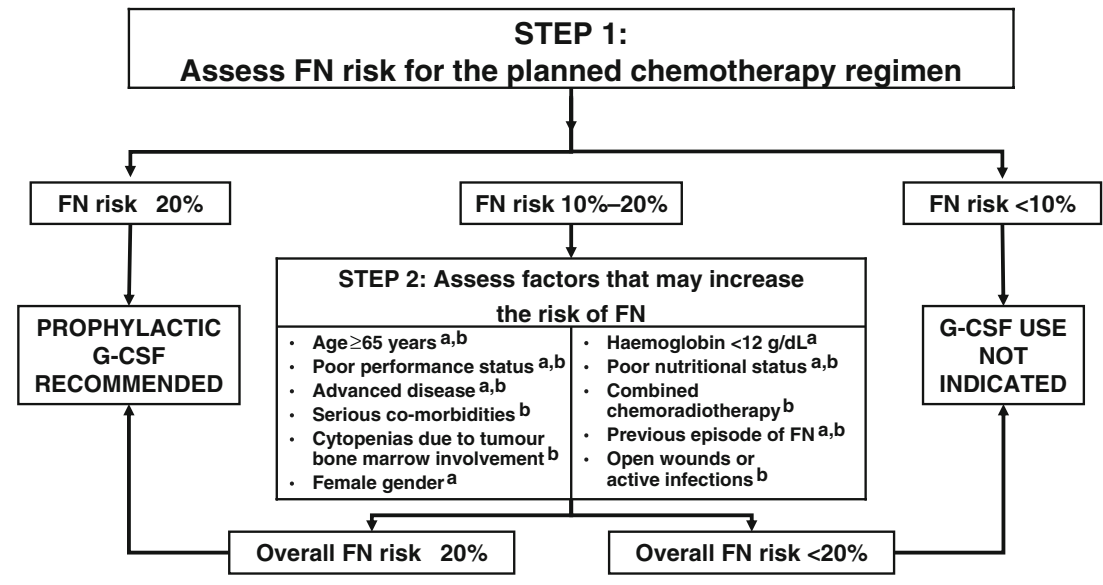

Fig. 1 Algorithm for determining whether granulocyte colonystimulating factor $(G-C S F)$ prophylaxis is indicated in patients undergoing chemotherapy (represents a combined interpretation of the 2006 G-CSF guidelines of the European Organisation for Research

\section{Development of risk models}

A number of groups have been developing predictive models to identify patients at increased risk of severe myelosuppression, low dose intensity and/or FN during chemotherapy for breast cancer [8, 39-42], NHL [8, 43, 44] or various cancer types [45-47]. The models are based on traditional risk factors such as age, gender, bodyweight and performance status, as well as disease type and stage, haematology/clinical chemistry, chemotherapy, whether GCSF was given and a previous history of FN (Table 1). A and Treatment of Cancer and the American Society of Clinical Oncology [16, 17]). $F N$ febrile neutropenia. Adapted from (a) Aapro et al. [16], with permission from Elsevier. Incorporating data from (b) Smith TJ et al. [17]

number of these have been validated retrospectively using existing patient datasets $[43,46]$.

Jenkins et al. demonstrated that patients receiving adjuvant 5-fluorouracil, epirubicin, cyclophosphamide (FEC) chemotherapy for breast cancer could be divided into five risk groups, in which the risk for neutropenic events ranged from $18 \%$ to $52 \%$, the risk of receiving suboptimal $(<85 \%)$ chemotherapy dose intensity from $9 \%$ to $36 \%$ and the risk of FN from $4 \%$ to $21 \%$, based only on their pretreatment absolute neutrophil and lymphocyte counts [40].

Table 1 Risk models for febrile neutropenia (FN) or severe haemotoxicity in patients receiving myelosuppressive chemotherapy

\begin{tabular}{|c|c|c|c|c|}
\hline & Dranitsaris et al. [39] & Pettengell et al. [44] & Ziepert et al. [43] & Lyman et al. [46] \\
\hline Regimen/disease & $\begin{array}{l}\text { Doxorubicin or } \\
\text { liposomal doxorubicin/ } \\
\text { metastatic breast cancer }\end{array}$ & Various/NHL & $\begin{array}{l}\text { CHOP-like regimens/ } \\
\text { NHL }\end{array}$ & Various \\
\hline $\begin{array}{l}\text { Risk assessed } \\
\text { by model }\end{array}$ & $\begin{array}{l}\text { Neutropenic } \\
\text { complications }^{\mathrm{a}}\end{array}$ & $\mathrm{FN}$ & $\begin{array}{l}\text { Anaemia; leucocytopenia; } \\
\text { thrombocytopenia }\end{array}$ & Neutropenia \\
\hline Basic characteristics & $\begin{array}{l}\text { Age } \geq 59 \text { years; } \\
\text { performance status }\end{array}$ & Age; bodyweight & $\begin{array}{l}\text { Gender; bodyweight; } \\
\text { performance status }\end{array}$ & Older age \\
\hline $\begin{array}{l}\text { Disease } \\
\text { characteristics }\end{array}$ & & & $\begin{array}{l}\text { Disease stage; bone } \\
\text { marrow involvement }\end{array}$ & \\
\hline $\begin{array}{l}\text { Haematology/clinical } \\
\text { chemistry }\end{array}$ & $\begin{array}{l}\text { Neutrophils } \leq 2 \times 10^{9} / 1 \\
\text { in previous cycle }\end{array}$ & Baseline albumin & $\begin{array}{l}\text { Baseline haemoglobin; } \\
\text { leucocytes; } \\
\text { thrombocytes; } \\
\text { GGT; LDH }\end{array}$ & $\begin{array}{l}\text { WBC; abnormal hepatic } \\
\text { or renal function }\end{array}$ \\
\hline Treatment factors & $\begin{array}{l}\text { Whether first cycle, } \\
\text { doxorubicin or } \\
\text { liposomal doxorubicin }\end{array}$ & $\begin{array}{l}\text { Planned cyclophosphamide, } \\
\text { cytarabine, etoposide } \\
\text { dose; G-CSF use }\end{array}$ & $\begin{array}{l}\text { Chemotherapy cycle } \\
\text { length; etoposide use; } \\
\text { vincristine dosage; } \\
\text { G-CSF use }\end{array}$ & $\begin{array}{l}\text { Various chemotherapy } \\
\text { agents; prior chemotherapy; } \\
\text { immunosuppressive } \\
\text { agents; G-CSF use }\end{array}$ \\
\hline History & & $\begin{array}{l}\text { Previous chemotherapy; } \\
\text { recent infection }\end{array}$ & First cycle FN & \\
\hline
\end{tabular}

CHOP cyclophosphamide, doxorubicin, vincristine, prednisone, GGT gamma glutamyltransferase, $L D H$ lactate dehydrogenase, NHL nonHodgkin's lymphoma

${ }^{\text {a }}$ Absolute neutrophil count $\leq 1.5 \times 10^{9}$ cells/1, FN or neutropenia with a documented infection 
Ziepert et al. [43] have developed a validated web-based tool for predicting the grade of haematological toxicity (leucopenia, thrombocytopenia and anaemia, but not specifically neutropenia) in lymphoma patients treated with CHOPlike therapies in clinical practice (www.toxcalculator.com). It was calculated that use of these models, which again stratify patients into five risk groups, could potentially spare intensive prophylactic strategies in $10-38 \%$ or $16-38 \%$ of patients, depending on whether cycle 1 data are available. Pettengell et al. [44] found that their model had high sensitivity $(81 \%)$ and specificity $(80 \%)$ for predicting cycle $1 \mathrm{FN}$ in patients with NHL, with a $28 \%$ positive and $98 \%$ negative predictive value.

Lyman et al. [46] developed a predictive model for neutropenic events that they retrospectively validated, using data from 4,458 patients treated for various cancers in clinical practice. The model demonstrated good discrimination, predicting cycle 1 neutropenic events in 34\% of high-risk and $4 \%$ of low-risk patients, with a sensitivity and specificity of $90 \%$ and $59 \%$, respectively. G-CSF primary prophylaxis was confirmed as a protective factor, and almost two thirds of patients in the validation dataset who were classified as high risk but did not receive primary GCSF prophylaxis subsequently received secondary G-CSF prophylaxis in later cycles.

Once prospectively validated, such models will be a valuable resource for helping to target G-CSF support.

\section{Dose-dense/intense treatment}

Shortening the time interval between chemotherapy cycles from the conventional 3-week, to a 2-week, cycle-dose densification - is thought to maximise tumour cell kill and minimise regrowth between cycles [48, 49]. Moreover, completion of chemotherapy within a shorter time frame may allow patients to resume their normal activities sooner. Earlier landmark studies with anthracycline/taxane regimens in breast cancer [50], CHOP-like regimens in aggressive lymphomas [51, 52] and doxorubicin/cyclophosphamide/ etoposide (ACE) chemotherapy in the small cell lung cancer (SCLC) setting [53] showed that dose densification significantly improves response and survival outcomes.

G-CSF has been central to the paradigm of dose-dense chemotherapy, as the short treatment cycle of 14 days would not otherwise allow sufficient time for bone marrow recovery between cycles. There is now a large body of new evidence for the efficacy of G-CSF (filgrastim or pegfilgrastim) in supporting delivery of dose-dense CHOP with or without rituximab, at full dose, on time in patients with NHL [54-57], including the elderly [54, 58, 59]. For instance, younger patients with intermediate-risk aggressive NHL were able to receive a dose-intense and dose-dense CHOP regimen (cyclophosphamide $1,000 \mathrm{mg} / \mathrm{m}^{2}$, doxoru- bicin $70 \mathrm{mg} / \mathrm{m}^{2}$, vincristine $2 \mathrm{mg}$ and prednisone $100 \mathrm{mg} \times$ 5 , delivered in $6 \times 14$-day cycles) with G-CSF support (filgrastim) [55]. G-CSF (pegfilgrastim) also supported delivery of dose-dense cyclophosphamide, doxorubicin, etoposide, vincristine, bleomycin, procarbazine and prednisone at full dose, on time in patients with Hodgkin's lymphoma [60].

In the breast cancer setting, several recent reports have documented the efficacy of pegfilgrastim in supporting delivery of dose-dense anthracycline/taxane regimens, including docetaxel followed by epirubicin/cyclophosphamide $(\mathrm{T} \rightarrow \mathrm{EC})$ or the reverse sequence $(\mathrm{EC} \rightarrow \mathrm{T})$ [61] and fluorouracil, epirubicin, cyclophosphamide $\rightarrow$ docetaxel $(\mathrm{FEC} \rightarrow$ Doc) [62], as well as FEC alone [63]. Dose-dense sequential doxorubicin plus cyclophosphamide followed by paclitaxel $(\mathrm{AC} \rightarrow \mathrm{T})$ was well tolerated when administered with pegfilgrastim and additional red cell support (darbepoetin alfa) in patients with haemoglobin $\leq 12 \mathrm{~g} / \mathrm{dl}$, with few chemotherapy dose reductions or episodes of FN $(<2 \%$ of patients) [64].

In patients with SCLC, full-dose, on-schedule, dosedense ACE chemotherapy was found to be feasible with pegfilgrastim support [65].

Use of G-CSF has also allowed investigation of higher chemotherapy dosages, but the benefits of dose escalation alone are presently unclear, suggesting that currently used dosages may already be optimal in most settings, provided that they can be delivered safely. For instance, significant dose escalations of cyclophosphamide, doxorubicin, vincristine, prednisone and etoposide (CHOEP) were possible with G-CSF support (filgrastim or lenograstim) in young patients with lymphoma [66], but this strategy did not enhance clinical benefits compared with standard CHOEP21 [67].

\section{Impact of G-CSF on chemotherapy delivery and survival outcomes}

Recent data from a large US survey (41,779 patients with FN treated at 115 medical centres) have highlighted the mortality risk associated with FN. Overall, in-hospital mortality was $9.5 \%$ and increased with the number of comorbidities: $2.6 \%$ in those without any major comorbidity, $10.3 \%$ in those with one major comorbidity and $>21 \%$ in those with more than one major comorbidity [3].

There are now much data to show that reduced chemotherapy dose intensity due to delays and dose reductions can potentially compromise survival outcomes in patients receiving curative treatment [7, 9-13, 68]. Even moderate reductions can negatively impact survival. For instance, in NHL patients treated with CHOP-like chemotherapy $(n=210)$, failure to achieve a relative dose intensity 
(RDI; the ratio of actual dose to planned dose of chemotherapy over the same time interval) of $>90 \%$ resulted in significantly shorter mean overall survival (2.24 vs. 5.38 years; $p=0.002$ ) [7].

The prospective Impact of Neutropenia in ChemotherapyEuropean observational study in breast cancer $(n=444)$ and lymphoma $(n=305)$ patients undergoing chemotherapy found that first-cycle $\mathrm{FN}$, age $\geq 65$ years and Eastern Cooperative Oncology Group (ECOG) performance score $>1$ were associated with low RDI in both groups of patients, with G-CSF primary prophylaxis protecting against low RDI in the lymphoma patients [8]. A meta-analysis of ten studies that reported RDI as an outcome found that average RDI in patients treated for solid tumours or lymphoma ranged from $91.0 \%$ to $99.0 \%$ (mean $95.1 \%$ ) in patients who received GCSF, compared with only 71.0 to $95.0 \%$ (mean $86.7 \%$ ) in those who did not [69].

There is now a growing body of evidence that improved chemotherapy delivery and reduction in FN with G-CSF [8, 69] may translate into better survival outcomes. Three meta-analyses of randomised studies comparing prophylactic G-CSF or granulocyte-macrophage colony-stimulating factor (GM-CSF) with placebo or no treatment have been conducted recently [69-71].

A meta-analysis of 17 studies compared primary prophylactic G-CSF (filgrastim, lenograstim or pegfilgrastim) with placebo or no treatment in 3,493 patients treated for solid tumours or lymphoma. In addition to improving RDI, G-CSF reduced the risk of infection-related mortality by $45 \%(1.5 \%$ vs. $2.8 \%$ : relative risk [RR] $0.55,95 \% \mathrm{CI}$ $0.33-0.90 ; p=0.018$ ) and early mortality (all-cause, during chemotherapy) by $40 \%$ (3.4\% vs. $5.7 \%$ : RR $0.60,95 \%$ CI $0.43-0.83 ; p=0.002$; Fig. 2$)$. As the patient populations in the studies included in this analysis tended to be relatively young and fit, it is possible that greater benefit of G-CSF might be seen in older populations [69].

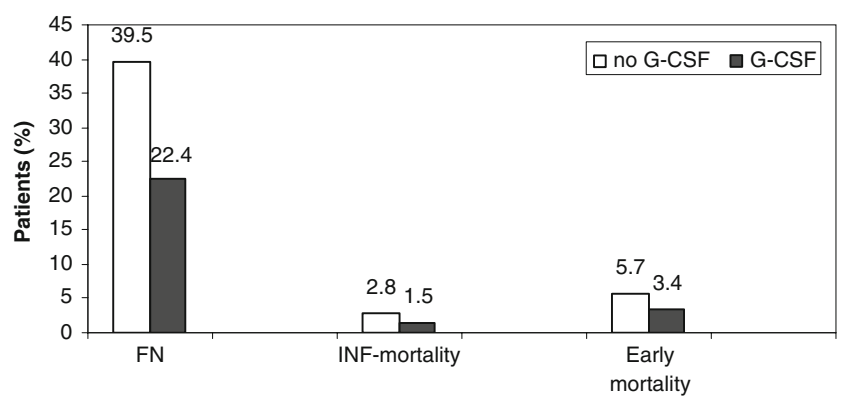

Fig. 2 Efficacy of primary prophylactic granulocyte colonystimulating factor ( $G-C S F$; pegfilgrastim, filgrastim or lenograstim) versus placebo or no treatment in preventing febrile neutropenia $(F N)$, infection-related mortality (INF mortality) and early mortality (allcause, during chemotherapy) in 3,493 patients treated with chemotherapy for solid tumours or lymphoma. Results of a meta-analysis of 17 studies [69]
However, a meta-analysis of 148 studies in a broad range of settings, including adults and children with cancer or undergoing stem cell transplantation, found prophylactic GCSF or GM-CSF to have little or no effect on early mortality (7.6\% vs. $8.0 \%$ of patients) or infection-related mortality $(3.1 \%$ vs. $3.8 \%)$ versus placebo/no treatment [70]. Nevertheless, G(M)-CSF did reduce the risk of documented infections (median $38.9 \%$ vs. $43.1 \%$; rate ratio 0.85 , 95\% CI 0.79 0.92 ) and microbiologically documented infections (median rate $23.5 \%$ vs. $28.6 \%$; rate ratio $0.86,95 \%$ CI $0.77-0.96$ ) [70]. Similarly, a recent Cochrane database review of 13 trials in patients treated for lymphoma $(n=2,607)$ did not find any benefit of G-CSF or GM-CSF on overall survival (HR 0.97, 95\% CI 0.87-1.09), freedom from treatment failure (HR 1.11, 95\% CI 0.91-1.35), complete response (RR $1.03,95 \%$ CI $0.95-1.10$ ) or infection-related mortality (RR $0.93,95 \%$ CI 0.51-1.71) [71].

The reasons for the differences between results of these three meta-analyses are not clear but probably relate to differences in individual study methodology and endpoints, as well as criteria for inclusion of studies. Both analyses that failed to show an effect of CSFs on mortality endpoints included studies that used GM-CSF (sargramostim or molgramostim) [70, 71], whereas the meta-analysis that demonstrated a survival benefit was restricted to studies of G-CSF [69]. It is thought that GM-CSF may be less effective than G-CSF in reducing FN and fever [72], and its use has been discontinued in Europe. In the USA, GM-CSF is not FDA-approved as an adjunct to standard myelosuppressive chemotherapy regimens in patients with solid tumours and lymphoma and has limited off-label use in this setting. Indeed, 61 of the 148 studies included in the Sung analysis used GM-CSF [70]. This analysis included transplant patients receiving high-dose chemotherapy, a different scenario from use of CSFs to support standarddose chemotherapy. Moreover, only the Kuderer analysis [69] was restricted to trials in which daily CSFs were to be given continuously until neutrophil recovery.

Nevertheless, all three meta-analyses confirmed a substantial FN risk reduction in patients receiving G-CSF/GMCSF support [69-71]. For instance, Kuderer et al. found that $\mathrm{FN}$ was reduced by $46 \%$ (22.4\% vs. $39.5 \%$ : RR 0.54 , 95\% CI 0.43-0.67; $p<0.001)$ [69].

Exploratory data from a prospective observational study conducted at 115 US practices ( $n=4,458$ patients) showed that pegfilgrastim significantly improved survival endpoints in patients with comorbidities who were receiving chemotherapy [73]. Of these patients, $41 \%$ were aged $>65$ years, $46 \%$ had ECOG performance score $>1$ and $38 \%$ had stage 4 disease. Patients receiving primary pegfilgrastim prophylaxis $(n=620)$ had better progression-free survival than those who did not, even after adjustment for other significant covariates. This study was not randomised, 
which limits firm conclusions, but these results are consistent with the G-CSF meta-analysis [69].

\section{Are the G-CSFs different?}

The non-PEGylated G-CSFs, standard G-CSF (filgrastim) and glycosylated G-CSF (lenograstim) appear to be broadly comparable in efficacy [16]. However, a growing body of evidence suggests that pegfilgrastim - a PEGylated formulation of filgrastim with neutrophil-regulated pharmacokinetics that is given as a single dose once per cycle $[57,74]$ - is more effective than filgrastim. A meta-analysis of five studies in a total of 617 patients treated for breast cancer or lymphoma showed that a single dose of pegfilgrastim was significantly more effective than 10-14 days of filgrastim in reducing FN (RR 0.64, 95\% CI 0.43-0.97) [75]. Data from the larger meta-analysis by Kuderer et al. [69] also suggest that pegfilgrastim was more effective than either lenograstim or filgrastim, although it must be noted that the pegfilgrastim data came from a single study (Fig. 3). These findings might reflect the sustained stimulation of bone marrow by pegfilgrastim throughout the period of neutropenia.
Moreover, the way that filgrastim is administered in realworld clinical practice (and some clinical trials) may compromise its efficacy. It should be given daily, until ANC returns to the normal range; data from registrational trials indicate that this requires approximately 9-14 injections per chemotherapy cycle $[14,76]$. However, it is common practice to administer fewer doses than this and/or to start treatment relatively late after chemotherapy [77-79]. Several analyses have shown that, when used in this manner, filgrastim may provide suboptimal protection against FN $[33,78,79]$. For instance, the Gepartrio study evaluated four different supportive regimens in consecutive cohorts of patients $(n=1,256$ total) receiving adjuvant TAC for breast cancer. FN occurred in $18 \%$ of patients who received an abbreviated course of daily G-CSF administered from days 5 to 10 . However, a single dose of pegfilgrastim on day 2 reduced the incidence of $\mathrm{FN}$ to $7 \%$; if ciprofloxacin was also incorporated into the prophylactic regimen, the risk was reduced to $5 \%$ (Fig. 4) [33].

An integrated analysis of data from 2,282 breast cancer patients compared pegfilgrastim primary prophylaxis with current-practice neutropenia management (a: no G-CSF or b: any G-CSF use other than protocol-specified pegfilgrastim

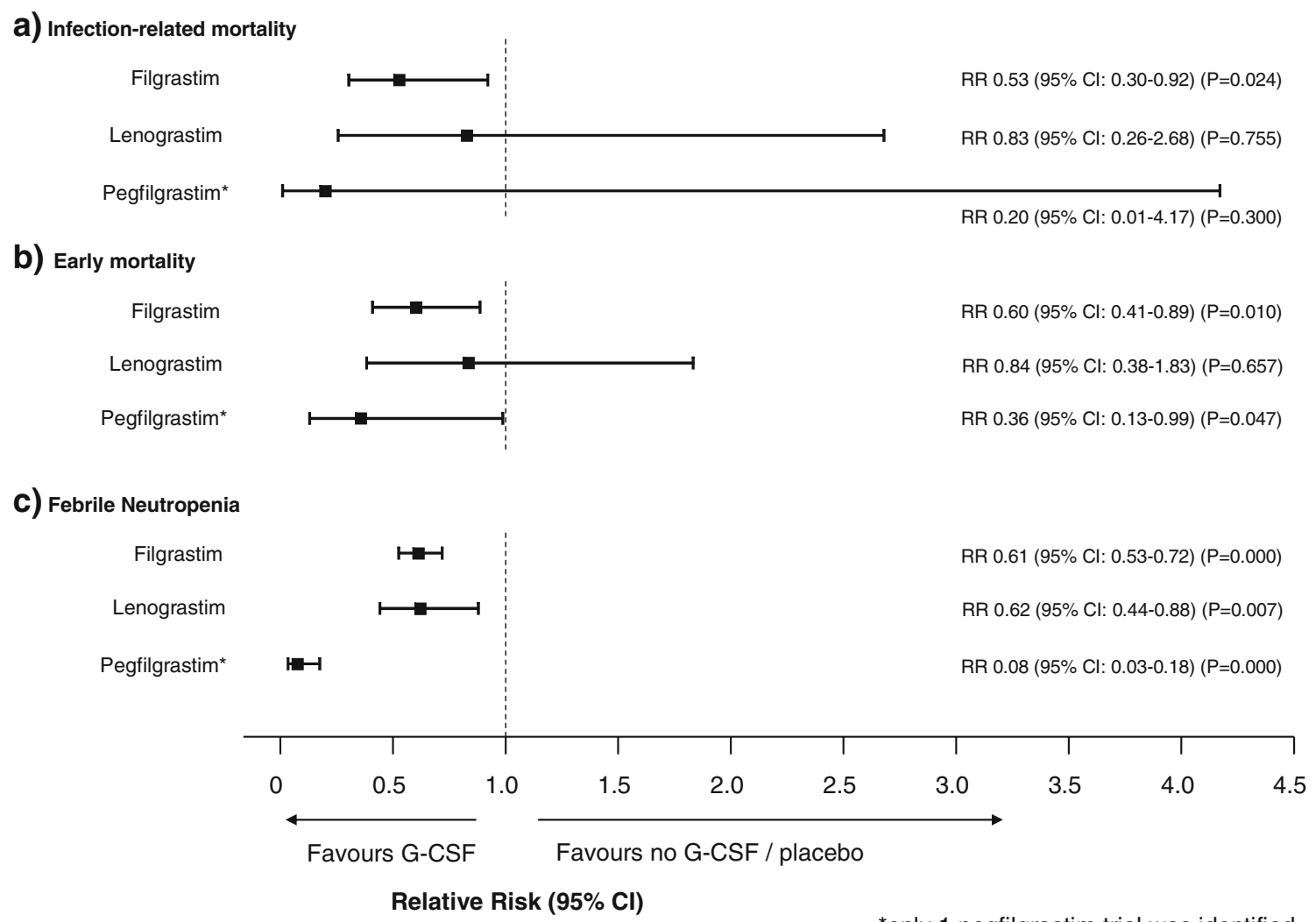

*only 1 pegfilgrastim trial was identified

Fig. 3 Efficacy of different granulocyte colony-stimulating factors in preventing infection-related mortality, early mortality and febrile neutropenia in 3,493 patients treated with chemotherapy for solid tumours or lymphoma. Forest plot of data from a meta-analysis of 17 randomised controlled studies comparing G-CSF primary prophylaxis with placebo or no treatment [69] 
A

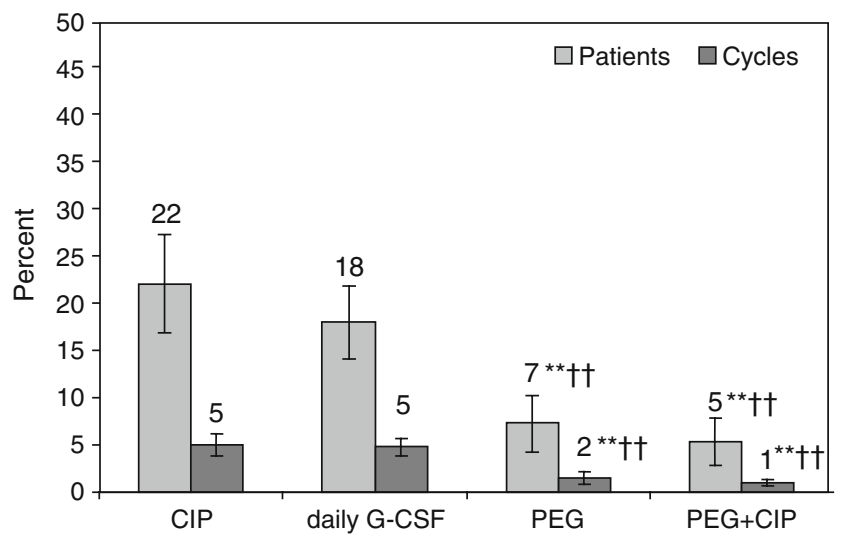

B

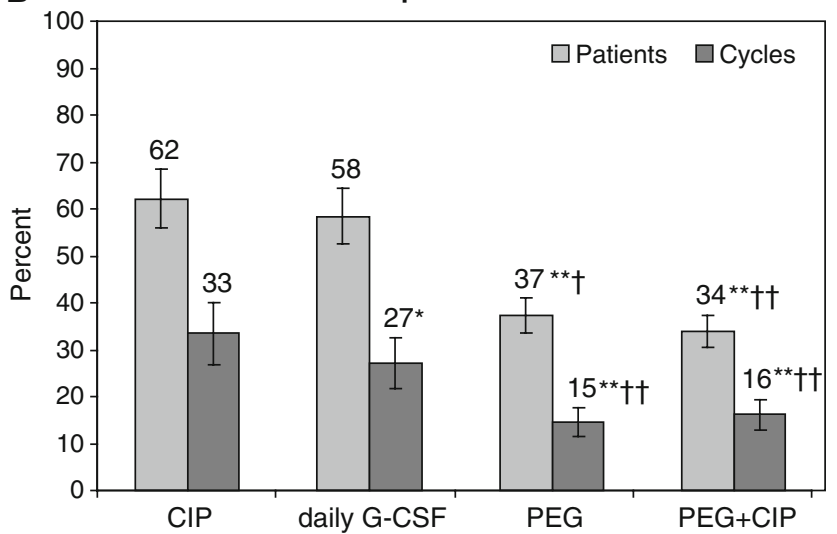

Fig. 4 Comparison of febrile neutropenia and grade 4 neutropenia incidence per patient and per cycle in patients receiving TAC chemotherapy for early breast cancer, supported by different primary prophylactic regimens: ciprofloxacin $500 \mathrm{mg}$ orally twice daily on days 5-14 ( $n=253$ patients), daily granulocyte colony-stimulating factor $\left(G-C S F\right.$; filgrastim $5 \mu \mathrm{g} / \mathrm{kg}$ per day or lenograstim $150 \mu \mathrm{g} / \mathrm{m}^{2}$ per day) on days 5-10 ( $n=374)$, pegfilgrastim $(P E G) 6 \mathrm{mg}$ on day 2 $(n=303)$ or pegfilgrastim plus ciprofloxacin (PEG+CIP; $n=314)$ [33]. ${ }^{*} p<0.01, * * p<0.001$ versus CIP; $\uparrow p<0.01, \dagger \dagger p<0.001$ versus daily G-CSF. Reprinted from von Minckwitz et al. [33]. By permission of Oxford Journals/European Society for Medical Oncology

primary prophylaxis) for supporting chemotherapy regimens associated with a moderately high/high FN risk [80]. The most common chemotherapy regimens were docetaxel or taxane/anthracycline combinations. Usage of primary G-CSF prophylaxis was low in the current-practice group: $75 \%$ of these patients did not receive any G-CSF prophylaxis in the first cycle. FN was markedly less frequent in the pegfilgrastim group compared with the current-practice group (5\% versus $29 \%$, adjusted for age, disease stage and study; adjusted odds ratio [OR] $0.124,95 \%$ CI $0.08-0.194 ; p<$ $0.0001)$. A subanalysis in elderly patients $(n=285$, aged $\geq 65$ years) showed similar results: FN occurred in $6 \%(95 \%$ CI $2-10 \%)$ of the pegfilgrastim group versus $24 \%$ (95\% CI $16-32 \%)$ of the current-practice group, while dose reductions occurred in $15 \%$ versus $29 \%$ of patients [37].
A retrospective US survey [77] of patients $(n=6,148)$ treated in 99 community oncology practices for various cancers also found that FN was more common in those who received filgrastim $(6.5 \%)$ than in those who received pegfilgrastim (4.7\%) [adjusted OR 1.41, 95\% CI 1.02-1.96; $p=0.040]$. However, whereas pegfilgrastim was administered within approximately 2 days after chemotherapy, filgrastim was started much later (mean $>7$ days and $>5$ days after chemotherapy in first and subsequent cycles, respectively), suggesting that filgrastim was used reactively instead of proactively. A similar analysis found that in community-based patients receiving various chemotherapy regimens (total of 15,763 cycles), the risk of hospitalisation was approximately $30 \%$ lower with pegfilgrastim support than with daily G-CSF [81].

Alternative versions of many innovative biopharmaceuticals, including G-CSF [82], are being developed. These "biosimilars" will not be identical to the corresponding original products because of differing protein sources and difficulties in replicating the complex proprietary manufacturing processes involved. While biosimilars may cost less, it is possible that small differences in biochemical and biophysical characteristics might translate into differences in potency and immunogenic potential [83].

\section{Tolerability issues}

Bone pain

Bone or musculoskeletal pain is a characteristic adverse event associated with G-CSF treatment. This is generally mild to moderate and can be managed with standard analgesics [84-86]. A large meta-analysis [69] found that bone or musculoskeletal pain was reported in approximately $20 \%$ of patients who received G-CSFs compared with approximately $10 \%$ of controls (RR $4.023,95 \%$ CI $2.156-$ 7.52; $p<0.0001)$. Arthralgia is also an adverse effect of taxane chemotherapy [87], which is often administered with G-CSF support. Filgrastim and pegfilgrastim were associated with similar incidences of bone pain in another large analysis (RR 0.95, 95\% CI 0.76-1.19) [75]. Although administering a lower-than-recommended dose of G-CSF (pegfilgrastim) was reported to be successful in reducing bone pain [88], this strategy obviously risks achieving suboptimal protection against FN [89], and it is at yet unclear whether bone pain is dose-related.

Other short-term adverse events

A proportion of patients may experience leucocytosis (white blood cell count $>100 \times 10^{9} / 1$ ) after receiving GCSFs $[64,84,90]$. At ANC recovery, pegfilgrastim 
clearance increases, resulting in a rapid decrease in serum concentrations. This resulted in less "overshoot" of ANC post-nadir compared with daily filgrastim [91]. Pegfilgrastim concentrations are negligible by day 12 and therefore unlikely to overstimulate neutrophil production [92].

G-CSFs can induce elevation of cancer antigen 15-3, a circulating marker of secreted products of the polymorphic MUC1 gene used for monitoring breast cancers, in breast cancer patients [93-96]. Physicians should be aware of the potential for this "false-positive" effect, which may occur via an increase in neutrophil counts or induction of MUC1 antigen [95]. There is no evidence that this is due to tumour stimulation.

\section{Secondary malignancies}

On the basis of retrospective data, it has been suggested that G-CSF/GM-CSF use might lead to a small increase in the risk of secondary malignancies. In patients treated with adjuvant chemotherapy for breast cancer, acute myeloid leukaemia or myelodysplastic syndrome (AML/MDS) occurred in 1.77\% of those who had received G-CSF or GM-CSF $(n=906)$ compared with $1.04 \%$ of those who had not $(n=4,604$; HR $2.14,95 \%$ CI 1.12-4.08) [97]. However, as acknowledged by the investigators, anthracyclines and cyclophosphamide may increase the risk of second malignancies in a doserelated manner [98-100]; administration of G-CSF may have allowed higher chemotherapy doses to be delivered, thereby confounding the analysis. Moreover, data from other studies, including a very large observational study $(n=64,715)$ [100], have not indicated an increased risk of secondary AML/ MDS with G-CSF use [50, 100, 101].

A recent meta-analysis found that although intensified chemotherapy with G-CSF support slightly increased the risk of second malignancies compared with standard chemotherapy without G-CSF, this was more than offset by the survival benefits [102]. Thus, the overall risk/benefit ratio continues to favour G-CSF use [103], as it facilitates chemotherapy delivery and prevents life-threatening FN.

\section{Clinical implications of new data}

Guidelines published from 2006 onwards have broadened the scope of G-CSF use for supporting chemotherapy delivery. There is now a large body of evidence for the efficacy of pegfilgrastim, as well as filgrastim, in supporting dose-dense chemotherapy and facilitating delivery of the full dose on time. Importantly, recent data have provided further (albeit indirect) evidence that appropriate primary G-CSF prophylaxis can potentially confer survival benefits in patients receiving chemotherapy in the curative setting.
FN risk should be assessed on an individual patient basis, taking into account the regimen, patient- and diseaserelated factors and treatment intent. Predictive tools that will help clinicians to identify which patients are most likely to benefit from G-CSF prophylaxis are now starting to become available, and these will allow more efficient targeting of patients at high risk.

Several studies have documented the considerable cost burden of FN in patients receiving chemotherapy $[1,3]$. An analysis in $>40,000$ US patients found that, on average, an FN episode resulted in a median hospital stay of 6 days and a median cost of $\$ 8,376$, with $35 \%$ of patients being hospitalised for at least 10 days [3]. Smaller studies from various western European countries have provided estimates of the average charge for FN-related hospitalisation ranging from $€ 2,619$ in Spain to $€ 4,931$ in France [4, 104, 105]. These findings highlight the need to implement official guidelines for preventing FN. A number of economic analyses have indicated that the costs of GCSFs can be at least partially offset by reduction of FN and its associated costs [106-108]. It should be noted that results of cost-effectiveness studies are dependent on the costs considered by each study, and such costs may differ between countries.

It is important that G-CSFs are used according to recommendations in order to gain the maximum benefit. In real-world clinical practice settings, patients often receive abbreviated courses of daily G-CSF treatment and this can reduce the level of FN protection obtained. Use of a single dose of pegfilgrastim per cycle in appropriate patients assures the delivery of adequate CSF support, providing a more convenient and potentially more effective strategy for assisting neutrophil recovery.

Prospective studies are needed to validate the importance of delivering the full dose intensity of standard chemotherapy regimens, integrated with G-CSF support where appropriate, across a range of tumour types. This will allow better quantification of the impact of both chemotherapy dose and supportive care in improving outcomes in cancer patients. These studies should also incorporate prospective evaluation of risk stratification for neutropenia and its complications, so that the use of both chemotherapy and GCSFs can be optimised in the most cost-effective way.

Acknowledgement Writing support (drafting, literature searching and co-ordination) for this manuscript was provided by Julia Balfour, Consultant Medical Writer, Kilconquhar, Scotland, with funding from Amgen (Europe), GmbH, Dammstrasse 23, 6301 Zug, Switzerland. Scientific staff at Amgen reviewed the manuscript and provided comments.

Author Contributions and Disclosures

The concept for the review was developed by MA and data collection directed by all three authors. The manuscript was drafted by JB in conjunction with MA and subsequently revised by JC and DK. The final version was approved by all three authors. 
MA has received remuneration as a consultant and advisor to Amgen, Chugai, Sanofi-Aventis and Roche. JC has received remuneration as a consultant and advisor to Amgen. DK has received remuneration as a speaker for Amgen.

Open Access This article is distributed under the terms of the Creative Commons Attribution Noncommercial License which permits any noncommercial use, distribution, and reproduction in any medium, provided the original author(s) and source are credited.

\section{References}

1. Caggiano V, Weiss RV, Rickert TS, Linde-Zwirble WT (2005) Incidence, cost, and mortality of neutropenia hospitalization associated with chemotherapy. Cancer 103:1916-1924

2. Courtney DM, Aldeen AZ, Gorman SM, Handler JA, Trifilio SM, Parada JP, Yarnold PR, Bennett CL (2007) Cancerassociated neutropenic fever: clinical outcome and economic costs of emergency department care. Oncologist 12:1019-1026

3. Kuderer NM, Dale DC, Crawford J, Cosler LE, Lyman GH (2006) Mortality, morbidity, and cost associated with febrile neutropenia in adult cancer patients. Cancer 106:2258-2266

4. Mayordomo JI, Castellanos J, Pernas S, Ruiz-Borrego M, Velasco A, Frau A, Lamas MJ, Lara N, Gasquet JA, Sánchez J (2006) Cost analysis of febrile neutropenia management of breast cancer patients in clinical practice in Spain. Ann Oncol 17 (Suppl 9):ix190-ix195, Abstract 617P

5. Elting LS, Lu C, Escalante CP, Giordano SH, Trent JC, Cooksley C, Avritscher EB, Shih YC, Ensor J, Bekele BN, Gralla RJ, Talcott JA, Rolston K (2008) Outcomes and cost of outpatient or inpatient management of 712 patients with febrile neutropenia. J Clin Oncol 26:606-611

6. Link BK, Budd GT, Scott S, Dickman E, Paul D, Lawless G, Lee MW, Fridman M, Ford J, Carter WB (2001) Delivering adjuvant chemotherapy to women with early-stage breast carcinoma: current patterns of care. Cancer 92:1354-1367

7. Bosly A, Bron D, Van Hoof A, De Bock R, Berneman Z, Ferrant A, Kaufman L, Dauwe M, Verhoef G (2007) Achievement of optimal average relative dose intensity and correlation with survival in diffuse large B-cell lymphoma patients treated with CHOP. Ann Hematol 87:277-283

8. Pettengell R, Schwenkglenks M, Leonard R, Bosly A, Paridaens R, Constenla M, Szucs TD, Jackisch C (2008) Neutropenia occurrence and predictors of reduced chemotherapy delivery: results from the INC-EU prospective observational European neutropenia study. Support Care Cancer 16:1299-1309

9. Bonadonna G, Valagussa P, Moliterni A, Zambetti M, Brambilla C (1995) Adjuvant cyclophosphamide, methotrexate, and fluorouracil in node-positive breast cancer: the results of 20 years of follow-up. N Engl J Med 332:901-906

10. Lee KW, Kim DY, Yun T, Kim DW, Kim TY, Yoon SS, Heo DS, Bang YJ, Park S, Kim BK, Kim NK (2003) Doxorubicin-based chemotherapy for diffuse large B-cell lymphoma in elderly patients: comparison of treatment outcomes between young and elderly patients and the significance of doxorubicin dosage. Cancer 98:2651-2656

11. Kwak LW, Halpern J, Olshen RA, Horning SJ (1990) Prognostic significance of actual dose intensity in diffuse large-cell lymphoma: results of a tree-structured survival analysis. J Clin Oncol 8:963-977

12. Chirivella I, Bermejo B, Insa A, Perez-Fidalgo A, Magro A, Rosello S, García-Garre E, Martín P, Bosch A, Lluch A (2009) Optimal delivery of anthracycline-based chemotherapy in the adjuvant setting improves outcome of breast cancer patients. Breast Cancer Res Treat 114:479-484
13. Pettengell R, Schwenkglenks M, Bosly A (2008) Association of reduced relative dose intensity and survival in lymphoma patients receiving CHOP-21 chemotherapy. Ann Hematol $87: 429-430$

14. Crawford J, Ozer H, Stoller R, Johnson D, Lyman G, Tabbara I, Kris M, Grous J, Picozzi V, Rausch G et al (1991) Reduction by granulocyte colony-stimulating factor of fever and neutropenia induced by chemotherapy in patients with small-cell lung cancer. N Engl J Med 325:164-170

15. Crawford J (2002) Neutrophil growth factors. Curr Hematol Rep 1:95-102

16. Aapro MS, Cameron DA, Pettengell R, Bohlius J, Crawford J, Ellis M, Kearney N, Lyman GH, Tjan-Heijnen VC, Walewski J, Weber DC, Zielinski C (2006) EORTC guidelines for the use of granulocyte-colony stimulating factor to reduce the incidence of chemotherapy-induced febrile neutropenia in adult patients with lymphomas and solid tumours. Eur J Cancer 42:2433-2453

17. Smith TJ, Khatcheressian J, Lyman GH, Ozer H, Armitage JO, Balducci L, Bennett CL, Cantor SB, Crawford J, Cross SJ, Demetri G, Desch CE, Pizzo PA, Schiffer CA, Schwartzberg L, Somerfield MR, Somlo G, Wade JC, Wade JL, Winn RJ, Wozniak AJ, Wolff AC (2006) 2006 Update of recommendations for the use of white blood cell growth factors: an evidence-based clinical practice guideline. J Clin Oncol 24:3187-3205

18. National Comprehensive Cancer Network (2010) Practice Guidelines in Oncology v.1.2010. Myeloid Growth Factors. Available at: http://www.nccn.org/professionals/physician_gls/PDF/myeloid growth.pdf. Accessed 2 Feb 2010

19. Greil R, Psenak O, Roila F (2008) Hematopoietic growth factors: ESMO recommendations for the applications. Ann Oncol 19 (Suppl 2):ii116-ii118

20. Carrato A, Paz-Ares Rodriguez L, Rodriguez Lescure A, Fernandez C, de Tejerina AM, Diaz Rubio Garcaa E, Perez Segura P, Constenla Figueiras M, García Carbonero R, Gómez Codina J, Lluch Hernández A, Maroto Rey JP, Martín Jiménez M, Mayordomo Cámara JI, Moreno Nogueira JA, Rueda Domínguez A (2009) Spanish Society of Medical Oncology consensus for the use of haematopoietic colony-stimulating factors in cancer patients. Clin Transl Oncol 11:446-454

21. Ozer H, Armitage JO, Bennett CL, Crawford J, Demetri GD, Pizzo PA, Schiffer CA, Smith TJ, Somlo G, Wade JC, Wade JL 3rd, Winn RJ, Wozniak AJ, Somerfield MR (2000) Update of recommendations for the use of hematopoietic colonystimulating factors: evidence-based, clinical practice guidelines. American society of clinical oncology growth factors expert panel. J Clin Oncol 18:3558-3585

22. Vogel CL, Wojtukiewicz MZ, Carroll RR, Tjulandin SA, BarajasFigueroa LJ, Wiens BL, Neumann TA, Schwartzberg LS (2005) First and subsequent cycle use of pegfilgrastim prevents febrile neutropenia in patients with breast cancer: a multicenter, doubleblind, placebo-controlled phase III study. J Clin Oncol 23:11781184

23. Timmer-Bonte JN, de Boo TM, Smit HJ, Biesma B, Wilschut FA, Cheragwandi SA, Termeer A, Hensing CA, Akkermans J, Adang EM, Bootsma GP, Tjan-Heijnen VC (2005) Prevention of chemotherapy-induced febrile neutropenia by prophylactic antibiotics plus or minus granulocyte colony-stimulating factor in small-cell lung cancer: a Dutch randomized phase III study. J Clin Oncol 23:7974-7984

24. Ajani JA (2008) Optimizing docetaxel chemotherapy in patients with cancer of the gastric and gastroesophageal junction: evolution of the docetaxel, cisplatin, and 5-fluorouracil regimen. Cancer 113:945-955

25. Posner M, Vermorken JB (2008) Induction therapy in the modern era of combined-modality therapy for locally advanced head and neck cancer. Semin Oncol 35:221-228 
26. Vermorken JB, Remenar E, van Herpen C, Gorlia T, Mesia R, Degardin M, Stewart JS, Jelic S, Betka J, Preiss JH, van den Weyngaert D, Awada A, Cupissol D, Kienzer HR, Rey A, Desaunois I, Bernier J, Lefebvre JL (2007) Cisplatin, fluorouracil, and docetaxel in unresectable head and neck cancer. N Engl J Med 357:1695-1704

27. Falco P, Cavallo F, Larocca A, Liberati AM, Musto P, Boccadoro M, Palumbo A (2008) Lenalidomide and its role in the management of multiple myeloma. Expert Rev Anticancer Ther $8: 865-874$

28. Palumbo A, Dimopoulos M, Miguel JS, Harousseau JL, Attal M, Hussein M, Knop S, Ludwig H, von Lilienfeld-Toal M, Sonneveld P (2009) Lenalidomide in combination with dexamethasone for the treatment of relapsed or refractory multiple myeloma. Blood Rev 23:87-93

29. Pal R, Roodman GD, Mapara M, Mocsinski L, List AF, Lentzsch S (2008) Immunomodulatory derivatives of thalidomide (IMiD)induced neutropenia is associated with PU1 downregulation and myeloid maturation arrest. Blood 112:Abstract 845

30. Repetto L, Biganzoli L, Koehne CH, Luebbe AS, Soubeyran P, Tjan-Heijnen VC, Aapro MS (2003) EORTC Cancer in the Elderly Task Force guidelines for the use of colony-stimulating factors in elderly patients with cancer. Eur J Cancer 39:2264-2272

31. Martin M, Pienkowski T, Mackey J, Pawlicki M, Guastalla JP, Weaver C, Tomiak E, Al-Tweigeri T, Chap L, Juhos E, Guevin R, Howell A, Fornander T, Hainsworth J, Coleman R, Vinholes J, Modiano M, Pinter T, Tang SC, Colwell B, Prady C, Provencher L, Walde D, Rodriguez-Lescure A, Hugh J, Loret C, Rupin M, Blitz S, Jacobs P, Murawsky M, Riva A, Vogel C (2005) Adjuvant docetaxel for node-positive breast cancer. N Engl J Med 352:2302-2313

32. Martin M, Lluch A, Segui MA, Ruiz A, Ramos M, Adrover E, Rodríguez-Lescure A, Grosse R, Calvo L, Fernandez-Chacón C, Roset M, Antón A, Isla D, del Prado PM, Iglesias L, Zaluski J, Arcusa A, López-Vega JM, Muñoz M, Mel JR (2006) Toxicity and health-related quality of life in breast cancer patients receiving adjuvant docetaxel, doxorubicin, cyclophosphamide (TAC) or 5-fluorouracil, doxorubicin and cyclophosphamide (FAC): impact of adding primary prophylactic granulocytecolony stimulating factor to the TAC regimen. Ann Oncol 17:1205-1212

33. von Minckwitz G, Kümmel S, du Bois A, Eiermann W, Eidtmann H, Gerber B, Hilfrich J, Huober J, Costa SD, Jackisch C, Grasshoff ST, Vescia S, Skacel T, Loibl S, Mehta KM, Kaufmann M (2008) Pegfilgrastim +/- ciprofloxacin for primary prophylaxis with TAC (docetaxel/doxorubicin/cyclophosphamide) chemotherapy for breast cancer. Results from the GEPARTRIO study. Ann Oncol 19:292-298

34. Romieu G, Clemens M, Mahlberg R, Fargeot P, Constenla M, Schutte M, Easton V, Skacel T, Bacon P, Brugger W (2007) Pegfilgrastim supports delivery of FEC-100 chemotherapy in elderly patients with high risk breast cancer: a randomized phase 2 trial. Crit Rev Oncol Hematol 64:64-72

35. Balducci L, Al-Halawani H, Charu V, Tam J, Shahin S, Dreiling L, Erchler WB (2007) Elderly cancer patients receiving chemotherapy benefit from first-cycle pegfilgrastim. Oncologist 12:1416-1424

36. Loibl S, von Minckwitz G, Harbeck N, Janni W, Elling D, Kaufmann M, Eggemann H, Nekljudova V, Sommer H, Kiechle M, Kümmel S (2008) Clinical feasibility of (neo)adjuvant taxane-based chemotherapy in older patients: analysis of $>4,500$ patients from four German randomized breast cancer trials. Breast Cancer Res 10:R77

37. Aapro M, Schwenkglenks M, Lyman GH, Lopez Pousa A, Lawrinson S, Skacel T, et al (2010). Pegfilgrastim primary prophylaxis vs. current practice neutropenia management in elderly breast cancer patients receiving chemotherapy. Crit Rev Oncol Hematol (in press)

38. Crawford J, Dale DC, Kuderer NM, Culakova E, Poniewierski MS, Wolff D, Lyman GH (2008) Risk and timing of neutropenic events in adult cancer patients receiving chemotherapy: the results of a prospective nationwide study of oncology practice. J Natl Compr Canc Netw 6:109-118

39. Dranitsaris G, Rayson D, Vincent M, Chang J, Gelmon K, Sandor D, Reardon G (2008) Identifying patients at high risk for neutropenic complications during chemotherapy for metastatic breast cancer with doxorubicin or pegylated liposomal doxorubicin: the development of a prediction model. Am J Clin Oncol 31:369-374

40. Jenkins P, Freeman S (2008) Pretreatment haematological laboratory values predict for excessive myelosuppression in patients receiving adjuvant FEC chemotherapy for breast cancer. Ann Oncol 20:34-40

41. Culakova E, Wolff D, Poniewierski M, Crawford J, Dale D, Lyman G (2008) Factors related to neutropenic events in early stage breast cancer patients. J Clin Oncol 26(Suppl 15):Abstract 634

42. Shayne M, Crawford J, Dale DC, Culakova E, Lyman GH (2006) Predictors of reduced dose intensity in patients with early-stage breast cancer receiving adjuvant chemotherapy. Breast Cancer Res Treat 100:255-262

43. Ziepert M, Schmits R, Trumper L, Pfreundschuh M, Loeffler M (2008) Prognostic factors for hematotoxicity of chemotherapy in aggressive non-Hodgkin's lymphoma. Ann Oncol 19:752-762

44. Pettengell R, Bosly A, Szucs TD, Jackisch C, Leonard R, Paridaens R, Constenla M, Schwenkglenks M (2009) Multivariate analysis of febrile neutropenia occurrence in patients with nonHodgkin lymphoma: data from the INC-EU Prospective Observational European Neutropenia Study. Br J Haematol 144:677-685

45. Lyman GH, Lyman CH, Agboola O (2005) Risk models for predicting chemotherapy-induced neutropenia. Oncologist $10: 427-437$

46. Lyman GH, Crawford J, Kuderer NM, Wolff D, Culakova E, Poniewierski MS, Dale DC (2008) Final risk prediction model for neutropenic complications in patients receiving cancer chemotherapy. Blood 112:Abstract 1312

47. Shayne M, Culakova E, Dale DC, Poniewierski MS, Wolff DA, Crawford J, Lyman H (2007) A validated risk model for early neutropenic events in older cancer patients receiving systemic chemotherapy. J Clin Oncol 25(Suppl 18):Abstract 9036

48. Norton L (1988) A Gompertzian model of human breast cancer growth. Cancer Res 48:7067-7071

49. Goldie JH, Coldman AJ (1979) A mathematic model for relating the drug sensitivity of tumors to their spontaneous mutation rate. Cancer Treat Rep 63:1727-1733

50. Citron ML, Berry DA, Cirrincione C, Hudis C, Winer EP, Gradishar WJ, Davidson NE, Martino S, Livingston R, Ingle JN, Perez EA, Carpenter J, Hurd D, Holland JF, Smith BL, Sartor CI, Leung EH, Abrams J, Schilsky RL, Muss HB, Norton L (2003) Randomized trial of dose-dense versus conventionally scheduled and sequential versus concurrent combination chemotherapy as postoperative adjuvant treatment of node-positive primary breast cancer: first report of Intergroup Trial C9741/Cancer and Leukemia Group B Trial 9741. J Clin Oncol 21:1431-1439

51. Pfreundschuh M, Trumper L, Kloess M, Schmits R, Feller AC, Rube C, Rudolph C, Reiser M, Hossfeld DK, Eimermacher H, Hasenclever D, Schmitz N, Loeffler M (2004) Two-weekly or 3weekly CHOP chemotherapy with or without etoposide for the treatment of elderly patients with aggressive lymphomas: results of the NHL-B2 trial of the DSHNHL. Blood 104:634-641

52. Pfreundschuh M, Trumper L, Kloess M, Schmits R, Feller AC, Rudolph C, Reiser M, Hossfeld DK, Metzner B, Hasenclever D, 
Schmitz N, Glass B, Rübe C, Loeffler M (2004) Two-weekly or 3-weekly CHOP chemotherapy with or without etoposide for the treatment of young patients with good-prognosis (normal LDH) aggressive lymphomas: results of the NHL-B1 trial of the DSHNHL. Blood 104:626-633

53. Thatcher N, Girling DJ, Hopwood P, Sambrook RJ, Qian W, Stephens RJ (2000) Improving survival without reducing quality of life in small-cell lung cancer patients by increasing the doseintensity of chemotherapy with granulocyte colony-stimulating factor support: results of a British Medical Research Council Multicenter Randomized Trial. Medical Research Council Lung Cancer Working Party. J Clin Oncol 18:395-404

54. Pfreundschuh M, Schubert J, Ziepert M, Schmits R, Mohren M, Lengfelder E, Reiser M, Nickenig C, Clemens M, Peter N, Bokemeyer C, Eimermacher H, Ho A, Hoffmann M, Mertelsmann R, Trümper L, Balleisen L, Liersch R, Metzner B, Hartmann F, Glass B, Poeschel V, Schmitz N, Ruebe C, Feller AC, Loeffler M (2008) Six versus eight cycles of bi-weekly CHOP-14 with or without rituximab in elderly patients with aggressive CD20+ B-cell lymphomas: a randomised controlled trial (RICOVER-60). Lancet Oncol 9:105-116

55. Verdonck LF, Notenboom A, de Jong DD, MacKenzie MA, Verhoef GE, Kramer MH, Ossenkoppele GJ, Doorduijn JK, Sonneveld P, van Imhoff GW (2007) Intensified 12-week CHOP (I-CHOP) plus G-CSF compared with standard 24-week CHOP (CHOP-21) for patients with intermediate-risk aggressive nonHodgkin lymphoma: a phase 3 trial of the Dutch-Belgian Hemato-Oncology Cooperative Group (HOVON). Blood 109:2759-2766

56. Brusamolino E, Rusconi C, Montalbetti L, Gargantini L, Uziel L, Pinotti G, Fava S, Rigacci L, Pagnucco G, Pascutto C, Morra E, Lazzarino M (2006) Dose-dense R-CHOP-14 supported by pegfilgrastim in patients with diffuse large B-cell lymphoma: a phase II study of feasibility and toxicity. Haematologica 91:496502

57. Mey UJ, Maier A, Schmidt-Wolf IG, Ziske C, Forstbauer H, Banat GA, Reber M, Strehl JW, Gorschlueter M (2007) Pegfilgrastim as hematopoietic support for dose-dense chemoimmunotherapy with R-CHOP-14 as first-line therapy in elderly patients with diffuse large B cell lymphoma. Support Care Cancer 15:877-884

58. Wolf M, Bentley M, Marlton P, Horvath N, Lewis ID, Spencer A, Herrmann R, Arthur C, Durrant S, van Kerkhoven M, MacMillan J, Mrongovius R (2006) Pegfilgrastim to support CHOP-14 in elderly patients with non-Hodgkin's lymphoma. Leuk Lymphoma 47:2344-2350

59. Hartmann F, Zeynalova S, Nickenig C, Reiser M, Lengfelder E, Duerk H, de Witt M, Schubert J, Loeffler M, Pfreunschuh MG (2007) Peg-filgrastim (Peg-F) on day 4 of (R-)CHOP-14 chemotherapy compared to day 2 in elderly patients with diffuse large B-cell lymphoma (DLBCL): results of a randomized trial of the German high-grade non-Hodgkin's lymphoma study group (DSHNHL). J Clin Oncol 25(Suppl 18):Abstract 19511

60. Engert A, Bredenfeld H, Dohner H, Ho AD, Schmitz N, Berger D, Bacon P, Skacel T, Easton V, Diehl V (2006) Pegfilgrastim support for full delivery of BEACOPP-14 chemotherapy for patients with high-risk Hodgkin's lymphoma: results of a phase II study. Haematologica 91:546-549

61. Piedbois P, Serin D, Priou F, Laplaige P, Greget S, Angellier E, Teissier E, Berdah JF, Fabbro M, Valenza B, Herait P, Jehl V, Buyse M (2007) Dose-dense adjuvant chemotherapy in nodepositive breast cancer: docetaxel followed by epirubicin/cyclophosphamide $(\mathrm{T} / \mathrm{EC})$, or the reverse sequence $(\mathrm{EC} / \mathrm{T})$, every 2 weeks, versus docetaxel, epirubicin and cyclophosphamide (TEC) every 3 weeks. AERO B03 randomized phase II study. Ann Oncol 18:52-57
62. Wildiers H, Dirix L, Neven P, Prove A, Clement P, Squifflet P, Amant F, Skacel T, Paridaens R (2009) Delivery of adjuvant sequential dose-dense FEC-Doc to patients with breast cancer is feasible, but dose reductions and toxicity are dependent on treatment sequence. Breast Cancer Res Treat 114:103-112

63. Kahan Z, Spanik S, Wagnerova M, Skacel T, Planko B, Fitzthum E, Lindner E, Soldatenkova V, Zielinski CC, Brodowicz T (2008) Feasibility of two dose-dense FEC regimens with growth factor support for adjuvant therapy in patients with early breast cancer: results from a randomised study of the Central European Cooperative Oncology Group (CECOG). Breast Cancer Res Treat 112:557-563

64. Burstein HJ, Parker LM, Keshaviah A, Doherty J, Partridge AH, Schapira L, Ryan PD, Younger J, Harris LN, Moy B, Come SE, Schumer ST, Bunnell CA, Haldoupis M, Gelman R, Winer EP (2005) Efficacy of pegfilgrastim and darbepoetin alfa as hematopoietic support for dose-dense every-2-week adjuvant breast cancer chemotherapy. J Clin Oncol 23:8340-8347

65. Pirker R, Ulsperger E, Messner J, Aigner K, Forstner B, Bacon P, Easton V, Skacel T (2006) Achieving full-dose, on-schedule administration of ACE chemotherapy every 14 days for the treatment of patients with extensive small-cell lung cancer. Lung 184:279-285

66. Trumper L, Zwick C, Ziepert M, Hohloch K, Schmits R, Mohren M, Liersch R, Bentz M, Graeven U, Wruck U, Hoffmann M, Metzner B, Hasenclever D, Loeffler M, Pfreundschuh M (2008) Dose-escalated CHOEP for the treatment of young patients with aggressive non-Hodgkin's lymphoma: I. A randomized dose escalation and feasibility study with bi- and tri-weekly regimens. Ann Oncol 19:538-544

67. Pfreundschuh M, Zwick C, Zeynalova S, Duhrsen U, Pfluger KH, Vrieling T, Mesters R, Mergenthaler HG, Einsele H, Bentz M, Lengfelder E, Trümper L, Rübe C, Schmitz N, Loeffler M (2008) Dose-escalated CHOEP for the treatment of young patients with aggressive non-Hodgkin's lymphoma: II. Results of the randomized high-CHOEP trial of the German High-Grade Non-Hodgkin's Lymphoma Study Group (DSHNHL). Ann Oncol 19:545-552

68. Earl HM, Hiller L, Dunn JA, Bathers S, Harvey P, Stanley A, Grieve RJ, Agrawal RK, Fernando IN, Brunt AM, McAdam K, O'Reilly S, Rea DW, Spooner D, Poole CJ (2008) NEAT: National Epirubicin Adjuvant Trial-toxicity, delivered dose intensity and quality of life. Br J Cancer 99:1226-1231

69. Kuderer NM, Dale DC, Crawford J, Lyman GH (2007) Impact of primary prophylaxis with granulocyte colony-stimulating factor on febrile neutropenia and mortality in adult cancer patients receiving chemotherapy: a systematic review. J Clin Oncol 25:3158-3167

70. Sung L, Nathan PC, Alibhai SM, Tomlinson GA, Beyene J (2007) Meta-analysis: effect of prophylactic hematopoietic colony-stimulating factors on mortality and outcomes of infection. Ann Intern Med 147:400-411

71. Bohlius J, Herbst C, Reiser M, Schwarzer G, Engert A (2008) Granulopoiesis-stimulating factors to prevent adverse effects in the treatment of malignant lymphoma. Cochrane Database Syst Rev (4):CD003189. http://mrw.interscience.wiley.com/cochrane/ clsysrev/articles/CD003189/frame.html

72. Dubois RW, Pinto LA, Bernal M, Badamgarav E, Lyman GH (2004) Benefits of GM-CSF versus placebo or G-CSF in reducing chemotherapy-induced complications: a systematic review of the literature. Supportive Cancer Ther 2(1):34-41

73. Lyman G, Kuderer N, Crawford J, Wolff D, Culakova E, Poniewierski M, Dale DC (2008) Impact of pegfilgrastim on early all-cause mortality in patients receiving cancer chemotherapy. J Clin Oncol 26(Suppl 15):Abstract 6552

74. Yang BB, Kido A, Shibata A (2007) Serum pegfilgrastim concentrations during recovery of absolute neutrophil count in 
patients with cancer receiving pegfilgrastim after chemotherapy. Pharmacotherapy 27:1387-1393

75. Pinto L, Liu Z, Doan Q, Bernal M, Dubois R, Lyman G (2007) Comparison of pegfilgrastim with filgrastim on febrile neutropenia, grade IV neutropenia and bone pain: a meta-analysis of randomized controlled trials. Curr Med Res Opin 23:2283-2295

76. Trillet-Lenoir V, Green J, Manegold C, Von Pawel J, Gatzemeier U, Lebeau B, Depierre A, Johnson P, Decoster G, Tomita D et al (1993) Recombinant granulocyte colony stimulating factor reduces the infectious complications of cytotoxic chemotherapy. Eur J Cancer 29A:319-324

77. Morrison VA, Wong M, Hershman D, Campos LT, Ding B, Malin J (2007) Observational study of the prevalence of febrile neutropenia in patients who received filgrastim or pegfilgrastim associated with 3-4 week chemotherapy regimens in community oncology practices. J Manag Care Pharm 13:337-348

78. Weycker D, Hackett J, Edelsberg JS, Oster G, Glass AG (2006) Are shorter courses of filgrastim prophylaxis associated with increased risk of hospitalization? Ann Pharmacother 40:402-407

79. Scott SD, Chrischilles EA, Link BK, Delgado DJ, Fridman M, Stolshek BS (2003) Days of prophylactic filgrastim use to reduce febrile neutropenia in patients with non-Hodgkin's lymphoma treated with chemotherapy. J Manag Care Pharm 9(2 Suppl):15-21

80. von Minckwitz G, Schwenkglenks M, Skacel T, Lyman GH, Pousa AL, Bacon P, Easton V, Aapro MS (2009) Febrile neutropenia and related complications in breast cancer patients receiving pegfilgrastim primary prophylaxis versus current practice neutropaenia management: results from an integrated analysis. Eur J Cancer 45:608-617

81. Weycker D, Malin J, Kim J, Barron R, Edelsberg J, Kartashov A, Oster G (2009) Risk of hospitalization for neutropenic complications of chemotherapy in patients with primary solid tumors receiving pegfilgrastim or filgrastim prophylaxis: a retrospective cohort study. Clin Ther 31:1069-1081

82. Del Giglio A, Eniu A, Ganea-Motan D, Topuzov E, Lubenau H (2008) XM02 is superior to placebo and equivalent to Neupogen in reducing the duration of severe neutropenia and the incidence of febrile neutropenia in cycle 1 in breast cancer patients receiving docetaxel/doxorubicin chemotherapy. BMC cancer $8: 332$

83. Mellstedt H, Niederwieser D, Ludwig H (2008) The challenge of biosimilars. Ann Oncol 19:411-419

84. Amgen (2008) Neulasta Summary of Product Characteristics. Available at: http://www.ema.europa.eu/humandocs/PDFs/EPAR/ neulasta/emea-combined-h420en.pdf. Accessed 2 Feb 2010

85. Amgen (2009) Neupogen summary of product characteristics. http://emc.medicines.org.uk/medicine/7907/SPC/Neupogen $+30 \mathrm{MU}+$ and $+48 \mathrm{MU}+$ Vials+and+Singleject+Syringes/. Accessed 2 Feb 2010

86. Holmes FA, Jones SE, O’Shaughnessy J, Vukelja S, George T, Savin M, Richards D, Glaspy J, Meza L, Cohen G, Dhami M, Budman DR, Hackett J, Brassard M, Yang BB, Liang BC (2002) Comparable efficacy and safety profiles of once-per-cycle pegfilgrastim and daily injection filgrastim in chemotherapyinduced neutropenia: a multicenter dose-finding study in women with breast cancer. Ann Oncol 13:903-909

87. Markman M (2003) Managing taxane toxicities. Support Care Cancer 11:144-147

88. Paba C, Sachdev J, Kronish L, Jahanzeb M, Waheed S (2008) Empiric dose reduction of pegfilgrastim in breast cancer patients receiving cytotoxic chemotherapy. J Clin Oncol 26(Suppl 15): Abstract 20636

89. Ip EJ, Lee-Ma A, Troxell LS, Chan J (2008) Low-dose filgrastim in patients with breast cancer treated with docetaxel, doxorubicin, and cyclophosphamide. Am J Health Syst Pharm 65:1552-1555
90. Chugai Pharma (2009) Granocyte (lenograstim) Summary of product characteristics. http://emc.medicines.org.uk/emc/assets/ $\mathrm{c} / \mathrm{html} /$ DisplayDoc.asp? DocumentID=8347. Accessed $2 \mathrm{Feb}$ 2010

91. Holmes FA, O’Shaughnessy JA, Vukelja S, Jones SE, Shogan J, Savin M, Glaspy J, Moore M, Meza L, Wiznitzer I, Neumann TA, Hill LR, Liang BC (2002) Blinded, randomized, multicenter study to evaluate single administration pegfilgrastim once per cycle versus daily filgrastim as an adjunct to chemotherapy in patients with high-risk stage II or stage III/IV breast cancer. J Clin Oncol 20:727-731

92. Yang BB, Hill R, Hollifield A, Green M, Holmes F, Sheridan W, Barnes RD (2003) Pegfilgrastim serum concentrations on the twelfth day after dosing are unlikely to stimulate granulopoiesis: a retrospective analysis of 6 clinical trials in a variety of cancer populations. Blood 102:Abstract 1918

93. Tyshler LB, Longton GM, Ellis GK, Livingston RB (1996) False positive tumor markers: elevation in patients with breast cancer on FAC-type chemotherapy and correlation with the development of hand-foot syndrome. Int J Biol Markers 11:203-206

94. Briasoulis E, Andreopoulou E, Tolis CF, Bairaktari E, Katsaraki A, Dimopoulos MA, Fountzilas G, Seferiadis C, Pavlidis N (2001) G-CSF induces elevation of circulating CA 15-3 in breast carcinoma patients treated in an adjuvant setting. Cancer 91:909917

95. Pentheroudakis G, Malamou-Mitsi V, Briasoulis E, Damala K, Vassou A, Vartholomatos G, Kolaitis N, Pavlidis N (2004) The neutrophil, not the tumor: serum CA 15-3 elevation as a result of granulocyte - colony-stimulating factor-induced neutrophil MU1C overexpression and neutrophilia in patients with breast carcinoma receiving adjuvant chemotherapy. Cancer 101:1767-1775

96. Saura C, Vilar E, Cortes J, Bellet M, Ocana A, Gomez P, Baselga J (2006) Pegfilgrastim induces elevation of serum CA 15-3 in breast carcinoma patients after receiving dose-dense adjuvant chemotherapy. J Clin Oncol 24(Suppl 18):Abstract 8595

97. Hershman D, Neugut AI, Jacobson JS, Wang J, Tsai WY, McBride R, Bennett CL, Grann VR (2007) Acute myeloid leukemia or myelodysplastic syndrome following use of granulocyte colony-stimulating factors during breast cancer adjuvant chemotherapy. J Natl Cancer Inst 99:196-205

98. Valagussa P, Moliterni A, Terenziani M, Zambetti M, Bonadonna G (1994) Second malignancies following CMF-based adjuvant chemotherapy in resectable breast cancer. Ann Oncol 5:803-808

99. Praga C, Bergh J, Bliss J, Bonneterre J, Cesana B, Coombes RC, Fargeot P, Folin A, Fumoleau P, Giuliani R, Kerbrat P, Hery M, Nilsson J, Onida F, Piccart M, Shepherd L, Therasse P, Wils J, Rogers D (2005) Risk of acute myeloid leukemia and myelodysplastic syndrome in trials of adjuvant epirubicin for early breast cancer: correlation with doses of epirubicin and cyclophosphamide. J Clin Oncol 23:4179-4191

100. Patt DA, Duan Z, Fang S, Hortobagyi GN, Giordano SH (2007) Acute myeloid leukemia after adjuvant breast cancer therapy in older women: understanding risk. J Clin Oncol 25:3871-3876

101. Clamp AR, Ryder WD, Bhattacharya S, Pettengell R, Radford JA (2008) Patterns of mortality after prolonged follow-up of a randomised controlled trial using granulocyte colony-stimulating factor to maintain chemotherapy dose intensity in non-Hodgkin's lymphoma. Br J Cancer 99:253-258

102. Lyman GH, Dale DC, Wolff D, Culakova E, Kuderer NM, Poniewierski MS, Crawford J (2008) Standard versus doseintensified chemotherapy with granulocyte colony-stimulating factor for malignant lymphoma: evaluation of risk for acute myeloid leukemia or myelodysplastic syndrome. Blood 112: Abstract 2390 
103. Touw IP, Bontenbal M (2007) Granulocyte colony-stimulating factor: key (f)actor or innocent bystander in the development of secondary myeloid malignancy? J Natl Cancer Inst 99:183-186

104. Viñolas N, Gúrpide A, Frau A, González Larriba J, Lamas M, Alvarez F, et al (2007) Clinical and economic impact of febrile neutropenia management of lung cancer patients in clinical practice in Spain (Abstract 6567). 14th European Cancer Conference; 23-27 September, Barcelona, Spain

105. Durand-Zaleski I, Vainchtock A, Bogillot O (2007) L'utilisation de la base nationale PMSI pour déterminer le côut d'un symptôme: le cas de la neutropénie fébrile. J Econ Med 25:269-280
106. Eldar-Lissai A, Cosler LE, Culakova E, Lyman GH (2008) Economic analysis of prophylactic pegfilgrastim in adult cancer patients receiving chemotherapy. Value Health 11:172-179

107. Lyman G, Lalla A, Barron R, Dubois RW (2009) Costeffectiveness of pegfilgrastim versus 6-day filgrastim primary prophylaxis in patients with non-Hodgkin's lymphoma receiving CHOP-21 in United States. Curr Med Res Opin 25:401-411

108. Ramsey SD, Liu Z, Boer R, Sullivan SD, Malin J, Doan QV, Dubois RW, Lyman GH (2009) Cost-effectiveness of primary versus secondary prophylaxis with pegfilgrastim in women with early-stage breast cancer receiving chemotherapy. Value Health $12: 217-225$ 